\title{
IMPACT OF CIRCULAR CONSTRUCTION ON DEMOLITION WASTE MANAGEMENT IN THE INDIAN CONSTRUCTION INDUSTRY
}

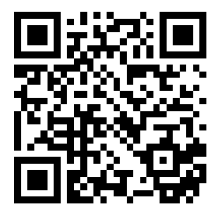

\author{
M Kranthi Kumar ${ }^{*}{ }^{凶}$, Rajan D ${ }^{2}$ \\ *1, 2 Department of Architecture, School of Planning and Architecture, India
}

DOI: https://doi.org/10.29121/ijetmr.v8.i1.2021.846

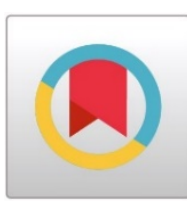

Article Citation: M Kranthi Kumar, and Rajan D. (2021). IMPACT OF CIRCULAR CONSTRUCTION ON DEMOLITION WASTE MANAGEMENT IN THE INDIAN CONSTRUCTION INDUSTRY. International Journal of Engineering Technologies and Management Research, 8(1), 12-24.

https://doi.org/10.29121/ijetmr.v8 i1.2021.846

Published Date: 31 January 2021

\section{Keywords:}

Demolition Waste Management Indian Construction Industry Current Trends Circular Construction Benefits Barriers

\begin{abstract}
In recent times due to the Indian economic growth, there is a surge in construction activities. This surge has led to an excess amount of demolition waste that is produced. According to the Building Material Promotion Council, India generates an estimated 150 million tons of $\mathrm{C}$ and D waste every year. Some existing initiatives and the significant stakeholders' involvement have created the demolition waste management systems essential in the building's demolition phase. The research in the $\mathrm{C}$ and $\mathrm{D}$ and Awareness program for $\mathrm{C}$ and $\mathrm{D}$ waste that initiated has led to the implementation of some waste management systems in the building's demolition phase. In India, the amount of demolition waste produced is higher than the construction waste produced while constructing buildings. So, it is essential for the demolition waste mitigation plan in the building's demolition phase. The study aims to know circular construction and current demolition waste management performance in the Indian construction industry. Through literature review, demolition waste management systems that are carried out all around the world are collected. The current practices carried out by different stakeholders practicing in India are known through a questionnaire survey. Data interpretation is made using the data collected in the literature review and the questionnaire survey. This research identified the significant benefits, barriers, and motivation factors to implement the waste management system, and proposing any necessary changes. Designer innovation and BIM deconstruction is considered as one of the barrier-breaking innovation in adopting the circular construction.
\end{abstract}

\section{INTRODUCTION}

Accelerated urbanization, industrialization, and a surge in economic activity put pressure on the construction industries in an urban area. In 2011 India had 370 million people in an urban place alone, which has been estimated to be doubled in 2030. In a recent decade, the Indian construction industry increased at an average rate of $10 \%$ yearly. Additionally, it has also been involved in increasing India's GDP from USD 20 billion to USD 60 billion in the past decade, 2000 to 2010. It has been estimated that this growth of India's GDP equals 8 percent[1] This increased growth in India has encouraged people to build more infrastructure, which leads to the demolition of the existing building to occupy the present scenario population growth in the urban place. In today's world, an enormous amount of material is extracted and consumed. It has been estimated that globally 35 tons of non-metallic minerals were

(C) 2021 The Author(s). This is an open access article distributed under the terms of the Creative Commons Attribution License, which permits unrestricted use, distribution, and reproduction in any medium, provided the original author and source are credited. 


\section{Kranthi Kumar, and Rajan D}

extracted in 2010. The main constituents are sand and gravel. It has been found that 6 percent of the global economy is circular. Materials in structures ought to support their worth, where structures should work as banks of significant materials and items. It could be possible by decreasing the amount of raw material used and good planning. Utilization of the 3R concept in the afterlife of the building could add to the action plan. [2] The waste products in the construction industry account for 30percent of landfill waste worldwide.[3]According to the Building Material Promotion Council, India generates an estimated 150 million tons of C and D waste every year[4] In India, the official recycling capacity is a meager 6,500 tons per day, just about one percent. Toxic dust particles from the debris were polluting the air when cities had to reduce their particulate pollution by $20-30$ percent by 2024 , under the ongoing National Clean Air Programme. From 21 billion sq. ft, the built-up area in 2005 is projected to rise almost five times to 104 billion sq. $\mathrm{ft}$ by 2030 (approximately).[1]Demolition is projected to occur in India from the decade 2020 to $2030[5]$

Table 1: Circular construction application

\begin{tabular}{|l|l|}
\hline Activity & Value \\
\hline New Construction & "40-60 $\mathrm{kgm}^{-2 "}$ \\
\hline Demolition of the existing building & "300 to $500 \mathrm{kgm}^{-2} "$ \\
\hline Repair for the building & "40 to $50 \mathrm{kgm}^{-2 "}$ \\
\hline
\end{tabular}

\section{Source: TIFAC}

The paper's main aim is to assess the circular construction impact on demolition waste management among multiple stakeholders in the Indian Construction Industry. Some of the significant objectives are to study and compare the current demolition waste management practices worldwide \& India mainly focused on the circular economy play in its demolition industry and analyzed the data collected in the literature review and questionnaire survey to assess the circular construction roleplay in the Indian construction industry. The research questions are

- What is the present stage of circular construction/closed-loop construction in the Indian construction industry to handle demolition waste?

- What is the extent of understanding circular construction for demolition waste management in the Indian construction industry among various Indian stakeholders?

- In implementing circular construction, what do different Indian stakeholders face bottlenecks?

\section{MATERIALS AND METHODS}

Research is based on collecting, analyzing, and interpreting data gathered in the Indian construction industry questionnaire survey. Data collection is done through online sources like an already published research paper, books, conference proceedings, etc.; Google Forms will be used in collecting the data in a questionnaire survey to have insight about obstacles faced in adopting the circular construction during the demolition phase of the building. The purpose of the research is to obtain knowledge about the present 3R techniques employed by different Indian stakeholders, and it is achieved through the questionnaire survey. To study large community actions, the questionnaire survey is always the best option when data needs to be collected more accurately. The data collected in the literature review and questionnaire survey are analyzed through the comparative study. From the comparative analysis, the conclusion and recommendations are drawn to improve the Indian construction industry. The future scope is derived using the conclusion and recommendation.

The stakeholders chosen for the questionnaire survey are Architects, Contractors like Builders, Consultants like MEP, Structural, firefighting, and Networking, Product manufacturers, and the client. These are some of the essential people in decision-making power when constructing/designing the infrastructure. No part of the highway or road development stakeholders is chosen. Only stakeholders who build the building are chosen. If there are some people or company practices both in a balanced manner, it is considered. 


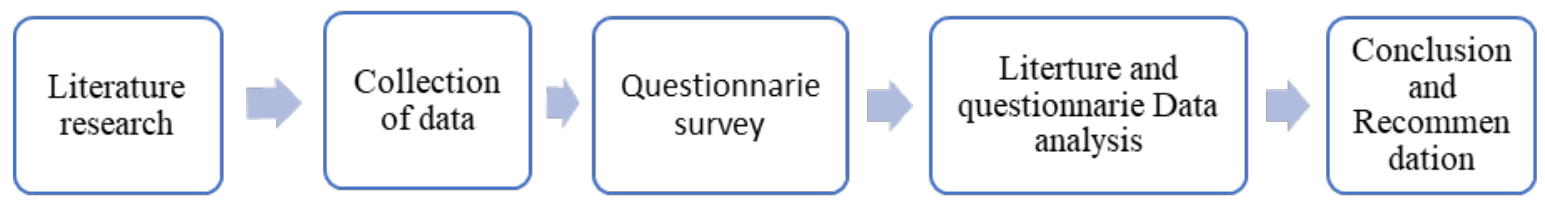

Figure 1: Methodology flow diagram

\section{LITERATURE SURVEY}

As this is a replicated study, the UK's study was tried to implement in India. Fourteen such papers were very relevant to my research and collected through online sources from well-known search engines. Moreover, it was filtered into two papers using specific criteria for reviewing, and inference is collected to move further in data collection for my research.

\subsection{PAPER REVIEW NO.1}

Paper 1: "Pathways to circular construction: An integrated management of construction and demolition waste for resource recovery." [2]

Authors: "Seyed Hamidreza Ghaffar, Matthew Burman, Nuhu Braimah"

Research type: Qualitative research

\subsubsection{AIM}

To investigate the current practices of UK CDW management and circular construction (reuse, recycle, and recovery of materials) concept awareness.

\subsubsection{METHODOLOGY}

The different stakeholders related to the Indian construction field have been chosen to review the UK CDW management status and circular construction. Moreover, the 2 main criteria have been taken up for the survey. It follows as (i) the Obstruction in CDW management and ii) Directives related to CDW and the concept of 3R in waste management. A review of data collected in the questionnaire survey has led to better recommendations for future studies.

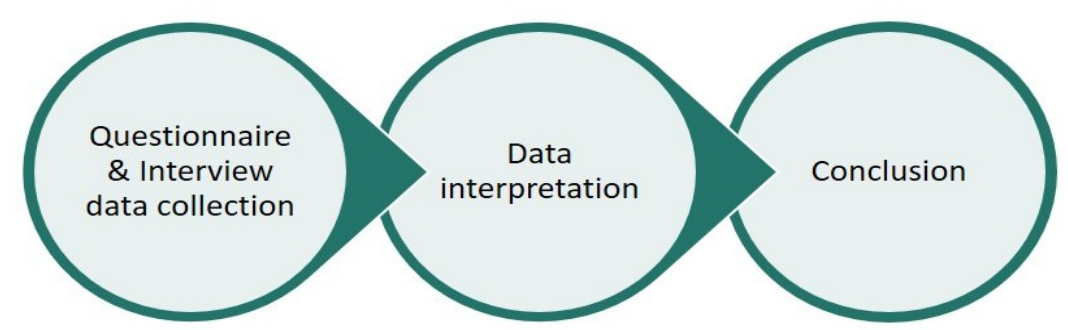

Figure 2: Methodology flow diagram

\subsubsection{INFERENCE}

For data collection, the questionnaire was framed in 3 parts:

- General view of the respondents,

- Processing and sorting of CDW issues.

- Research Paper discusses the 3R concept. 
Some of the critical topics discussed after the questionnaire review are bottlenecks in circular construction: Difficulties in CDW recycling and reuse are itemized according to the questionnaire survey results.

- Storage of waste material (40 percent)

- $\quad$ cost (30 percent)

- The organization, Health and Safety regulations (12 percent)

- 6 percent of people suggested other reasons

Awareness about UK CDW, circular construction: To review the awareness questions like "Do you believe that closed-loop construction gets enough promotion?", "Would your company be interested in future investments/strategies associated with the circular economy?"

Evaluation of current practice: Requirement of high skilled labor, high resources like time, equipment power consumption, treatment of waste before utilization process associated with this type makes it cost very high compared to the conventional method

CDW management strategies towards circular construction:

- Strict rules and regulations

- Factory-made building components

- Adequate motivation/encouragement to stakeholders

\subsubsection{CONCLUSION}

Stakeholder participation, on-site sorting, and logistics are essential aspects that need to be taken care of. The involvement of various stakeholders, private companies, and the government must be organized. Marketing for the $3 \mathrm{R}$ concept is not provided to the required amount to reach all stakeholders, and Artificial intelligence usage in the $3 \mathrm{R}$ concept will increase its adaptability. There is also a requirement of tool and protocol so that investors can compel that in adopting the circular construction concept.

\subsection{PAPER REVIEW NO.2}

Paper 2: Circular economy in construction: current Awareness, challenges, and enablers.[6] Authors: Katherine Tebbatt Adams, Mohamed Osmani, Tony Thorpe, Jane Thornback Research type: Qualitative research

\subsubsection{AIM}

Investigate the construction industry viewpoint about recognition, difficulties, and facilitators in the 3R concept.

\subsubsection{METHODOLOGY}

From online sources, both the quantitative and qualitative data were collected and used in the research. The questionnaire survey was conducted for the data collected from various practicing stakeholders, so both a qualitative and quantitative approach was made in this research. Results are analyzed and discussed after the questionnaire survey, from which conclusions and recommendations are made.

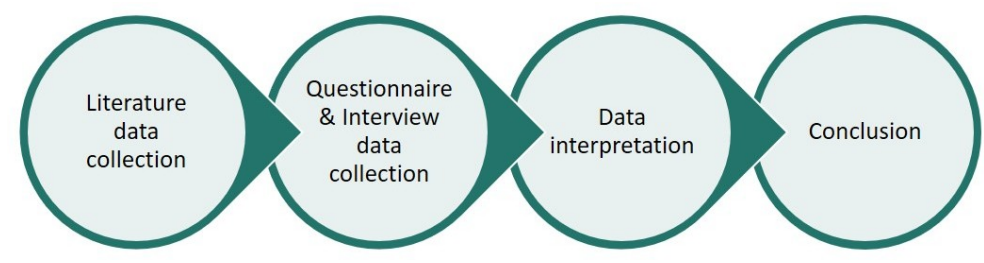

Figure 3: Methodology flow diagram 
Impact of Circular Construction on Demolition Waste Management in The Indian Construction Industry

\subsubsection{INFERENCE}

Some of the principles of CE explained in this paper are listed below,

- "Increasing the productivity of materials by doing the same or more with less eliminating."

- "Eliminating waste by defining materials as either technical or biological nutrients enabling them to be within closed material loops; 'waste as food'"

- "Maintaining or increasing the value of materials, environmentally and economically."

3R concept in demolition's recognition, difficulties, and facilitators was explored by a questionnaire survey with various construction industry stakeholders.

Challengers in circular construction are interest lack; Supply chain awareness, Circular economy knowledge lack, Incentives for motivating its usage, end of life issues in consideration, Recovery mechanism, Unclear financial cases, the low value of end-of-life products, Fragmented supply chain, and Building complexity.

Enablers in circular construction are awareness-raising campaign, Secondary material assurance scheme, Case study of best practice, Incentives to use secondary material, Value of material measure, Design tools and guidance, Technology to recover the material, Take back scheme viability, Clear business case.

From the result of the questionnaire, three central themes were picked and discussed to get more clarity.

Significant value in Circular construction: The primary funding may not directly advantageous, and the end owner may get the advantage. So, knowledge of the profitability of the $3 \mathrm{R}$ concept is required for every party involved. Keeping the initial cost low may invalidate future value, which is an issue in the construction industry.

Organization issues: Fragmentation in the construction industry is the major drawback in its adoption. By exploring the procurement, supply chain management activities, Collaboration can be improved. Collaboration is a significant factor in circular construction development.

Technical issues: Technical issue is considered as one of the significant problems that need to overcome. By adopting energy-efficient buildings, contemporary methods of construction, and smart buildings, it can be resolved.

\subsubsection{CONCLUSION}

For encouraging circular construction usage, the design should consider adaptability, flexibility, and deconstruction afterlife. The organizational, technical, and economic issues can resolve by adopting the various frameworks. For adopting the 3R concept, Feasible take-back schemes, high-value markets, affirmation schemes for reused materials, ideal case studies, and awareness programs are some of the facilitators. Stimulant shortage to design for afterlife issues, technology insufficient in max recovery, and an unclear financial case are significant difficulties for the UK construction industry. These are ranked from the survey responses.

\subsection{OTHER LITERATURE DATA COLLECTION}

\subsubsection{BUILDINGS - AFTERLIFE SCENARIO}

There is a limited lifespan for each building. Few buildings stand for 100 years and above. After demolition, general possibilities are suitable dependent on resources like money, surrounding aspects, and some other issues like conservation orders. [7]

- Deconstruction: Selective demolition.

- Reuse of structure: It some cases, even the foundation/column can be retained, and the rest will be demolished to start with new construction

- Demolition: Destroying the whole building and 3R must be analyzed before the waste ends up in a landfill

Consideration of reusing the entire building or even a whole house must be adopted to decrease the environment's negative impact. No waste is produced if a whole building can be deconstructed and reconstructed elsewhere. It is called 'deconstruction design.' If this is possible, it is taken into consideration before the building.

If so, there is no possibility of reusing; then the material must be processed for recycling rather than disposing of the economic value products in a landfill. Reuse and recycling were divided into three steps: [7]

International Journal of Engineering Technologies and Management Research 
First-order: For all sorts of metals and glass, first-order recycling is possible. Steel is the most recycled commodity in the world.

Second-order: At times, the purpose it served before demolition, and after the demolition, it changes. The best example could be concrete, where the practicality of using the concrete after demolition could not serve the same purpose as concrete itself. In contrast, it can be used as some product in the making of concrete.

Third-order: Recycling of the third-order concerns thermal utilization. Not much in use as a result of environmental contamination.

\subsubsection{WASTE GENERATORS AND COMPOSITION OF DEMOLITION WASTE IN INDIA}

High waste generators \& small waste generators are two classifications when talking about demolition waste in India, given in figure 1.4. The high waste generators are mostly found in big infrastructure projects. The real estate industry consists of developing homes, industrial and commercial facilities, the demolition of unauthorized buildings, etc., as retail or small generators, small industrial businesses, and independent house building teams are considered. The project activities should be coordinated by all workers involved at any level for total waste reduction.

Numerous materials come after the building is destroyed. The dirt, asphalt, and concrete occupy 80 percent. Reclamation will decrease the burden on the procurement of 100 percent of raw material, and some percentage of recycled material will be used for manufacturing.[9]

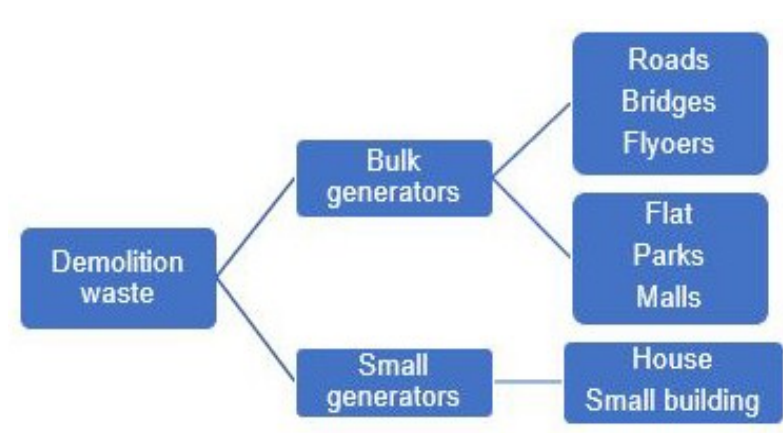

Figure 4: Sources of demolition waste

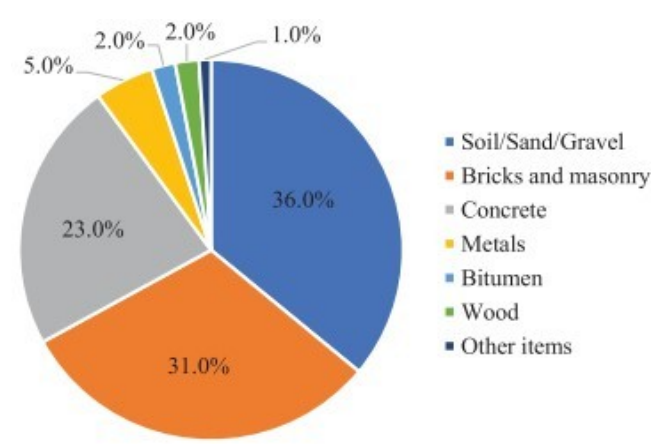

Figure 5: Typical CD waste composition in India

\subsubsection{COMPARATIVE STUDY BETWEEN THE EUCONSTRUCTION INDUSTRY AND INDIAN CONSTRUCTION INDUSTRY BASED ON CIRCULAR CONSTRUCTION}

One primary reason the EU has explored more possibilities in adopting Circular construction is the Landfill tax imposition, which has encouraged many stakeholders to adopt this construction type. May be imposing such a strict landfill tax may encourage the stakeholders to explore more possibilities in circular construction, which decreases the waste ending up landfill even it saves economically. Statistically, the UK revenue graph data shows that the revenue of landfill tax in the past five years has seen a downfall after attaining its peak in 2014 .

Table 2: Circular construction initiatives

\begin{tabular}{|c|c|c|}
\hline Action & EU's Circular construction & India's circular construction \\
\hline Incentive & $\begin{array}{l}\text { The incentive concept has been introduced } \\
\text { recently. }\end{array}$ & There is no incentive. \\
\hline Resale market & $\begin{array}{c}\text { There is a separate website where the buyer and } \\
\text { seller can contact directly for selling the } \\
\text { deconstructed products.[10] }\end{array}$ & $\begin{array}{l}\text { There is no easy way to communicate. There } \\
\text { are some resale markets offline only.[9] }\end{array}$ \\
\hline $\begin{array}{l}\text { Recovery based } \\
\text { design }\end{array}$ & $\begin{array}{c}\text { Some case studies have been set as an example for } \\
\text { upcoming projects. }\end{array}$ & There are no such case studies in India. \\
\hline $\begin{array}{c}\text { Target in } \\
\text { legislation }\end{array}$ & $\begin{array}{c}\text { There is a target of } 70 \% \text { of waste that needs to be } \\
\text { recycled in } 2020 \text { in legislation [8] }\end{array}$ & $\begin{array}{l}\text { There is no such target that has been } \\
\text { established in legislation[11] }\end{array}$ \\
\hline
\end{tabular}


Impact of Circular Construction on Demolition Waste Management in The Indian Construction Industry

\begin{tabular}{|c|c|c|}
\hline Recycling plants & $\begin{array}{l}\text { There is the availability of an optimum recycling } \\
\text { plant in and around the area of construction or } \\
\text { deconstruction. [8] }\end{array}$ & $\begin{array}{l}\text { There is a lack of recycling plants available in } \\
\text { some areas around India. }\end{array}$ \\
\hline Law & $\begin{array}{l}\text { There is strict law enforcement, which makes it } \\
\text { mandatory to be followed.[8] }\end{array}$ & $\begin{array}{c}\text { There is a law for bulk waste producers only } \\
\text { that too not followed strictly even in } \\
\text { metropolitan cities }\end{array}$ \\
\hline $\begin{array}{c}\text { Demolition } \\
\text { codebook }\end{array}$ & $\begin{array}{l}\text { The European Commission has established a } \\
\text { detailed protocol and guideline for waste } \\
\text { management to demolish a structure[10] }\end{array}$ & $\begin{array}{c}\text { No such protocol for waste management has } \\
\text { been published, but there is a demolition } \\
\text { codebook IS 4130:1991.[12] }\end{array}$ \\
\hline BIM utilization & $\begin{array}{l}\text { There is an initialization to start the usage of BIM } \\
\text { in deconstruction[10] }\end{array}$ & $\begin{array}{c}\text { There is no discussion regarding the usage of } \\
\text { BIM in deconstruction. Its potential is not } \\
\text { fully explored. }\end{array}$ \\
\hline $\begin{array}{l}\text { Exploration in } \\
\text { its application }\end{array}$ & $\begin{array}{c}\text { Many applications have been explored in research } \\
\text { for circular construction, which has been } \\
\text { mentioned in table 1.1.[8] }\end{array}$ & $\begin{array}{l}\text { Few applications have been explored in } \\
\text { research for circular construction.[13] }\end{array}$ \\
\hline
\end{tabular}

\section{RESULTS AND DISCUSSIONS}

\subsection{RESULTS}

The questionnaire was sent to 200 people approx. Only 79 people have responded to it, which states that this research has a response rate of 39.5\%. The following segment is divided into the description profile of appellants, knowledge level assessment, and a summary of the significant obstacles and motivators.

\subsubsection{DESCRIPTION OF THE RESPONDENTS}

The questionnaire comprised of a profile like Designer (82\%), Contractor (8\%), Consultant (8\%), the Product manufacturer (1\%), Owner/client (1\%). 2 demolition contractors from the Tamilnadu have been interviewed in telephonic conversation to understand the scenario of India's current demolition waste management plan. Moreover, these two are members of the Indian Demolition Association.

The survey has comprised of various work experience of the respondents, i.e., 0-3years (75\%), 3-5years (15\%), 5 -10years (5\%), above 15years (5\%). The survey comprised of responses from various locations, i.e., Northern (20\%), Southern (65\%), Eastern (7\%), Western (8\%).

\subsubsection{CIRCULAR CONSTRUCTION PERCEPTION AND INTEREST IN THE INDIAN CONSTRUCTION INDUSTRY}

The following table no.3 below, summarizes the questionnaire survey data collected to analyze the different stakeholders' perceptions, interests, and knowledge about the circular construction.

Table 3: Questionaries survey weightage results

\begin{tabular}{|c|c|c|c|}
\hline \multirow[t]{2}{*}{ Question } & \multicolumn{3}{|c|}{$\begin{array}{l}\text { Answers in } \\
\text { percentage }\end{array}$} \\
\hline & Yes & No & Maybe \\
\hline $\begin{array}{l}\text { Are they appeased with present India's legislation/law for Demolition Waste (i.e., } \\
\text { disposal tax)? }\end{array}$ & $12 \%$ & $66 \%$ & $22 \%$ \\
\hline $\begin{array}{c}\text { Is there a reduction in India's Demolition Waste generation due to the current waste } \\
\text { management plan? }\end{array}$ & $33 \%$ & $41 \%$ & $24 \%$ \\
\hline Are they appeased with the current salvaging processes in the industry? & $12 \%$ & $88 \%$ & - \\
\hline $\begin{array}{l}\text { Is there enough concession/acknowledgment is provided (e.g., LEED/GRIHA score) for } \\
\text { recycling Demolition Waste? }\end{array}$ & $42 \%$ & $58 \%$ & - \\
\hline
\end{tabular}




\begin{tabular}{|c|c|c|c|}
\hline $\begin{array}{l}\text { If no, would more concession/acknowledgment enable you to recycle Demolition } \\
\text { Waste? }\end{array}$ & $79 \%$ & $2 \%$ & $19 \%$ \\
\hline Have you worked on assessing the site and devising for Demolition Waste valorization? & $19 \%$ & $81 \%$ & - \\
\hline $\begin{array}{l}\text { Do you have worked on demolition estimates for the categorization of Demolition Waste } \\
\text { streams? }\end{array}$ & $13 \%$ & $77 \%$ & - \\
\hline Conscious of the enforcement passed for practicing circular construction in India? & $26 \%$ & $74 \%$ & - \\
\hline Are you conscious of circular construction? & $47 \%$ & $53 \%$ & - \\
\hline Agree that sufficient breakthrough is provided for circular construction? & $19 \%$ & $81 \%$ & - \\
\hline Conscious about reversible building design concept? & $53 \%$ & $47 \%$ & - \\
\hline If yes, Will you be using this concept in your present/near future projects? & $43 \%$ & $1 \%$ & $56 \%$ \\
\hline
\end{tabular}

The same survey was conducted with a member of India's Demolition Association, who has experienced more than 15 years in the demolition field. He also clearly states that "the Indian demolition industry is not in much good state as of now, and it needs much more improvement in upcoming days to decrease the waste ending up in the landfill." According to him, time

Consumption is the primary factor that is the hindrance in adopting circular construction.

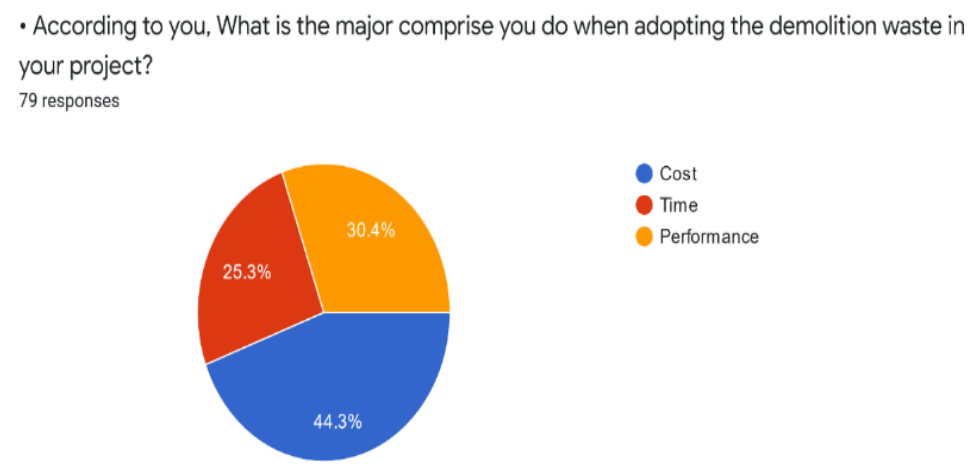

Figure 6: Bar chart for analyzing the status of recycling product

Overall, his words were, "There is much more improvement needed in adopting the circular

Construction, and it needs to be promoted as much in the engineers and architects' curriculum for the welfare of society." Some of the crucial questions which provided a clear idea about our position of adopting waste management are "What stage are we in the usage of recycled products for New construction?" and "According to you, what is the major comprise you do when adopting the demolition waste in your project?". The survey answers for these questions are summarized in figure

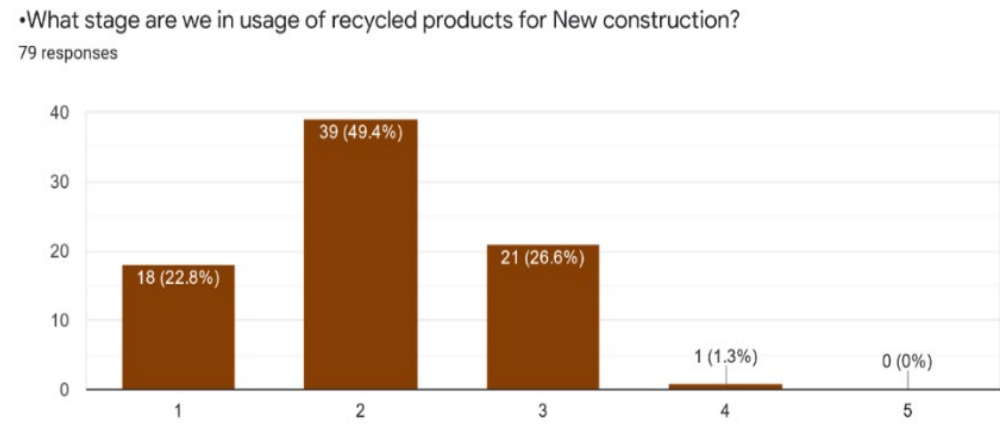

Figure 7: Major constraints in adopting circular construction 


\subsubsection{OBSTACLES AND ENABLERS OF CIRCULAR CONSTRUCTION}

The survey participants have been requested to rate the importance of different obstacles and enablers for adopting circular construction. (for obstacles \& enablers:' 1'-No were matched,' 5'- very closely matched)

\section{Significant Enablers}

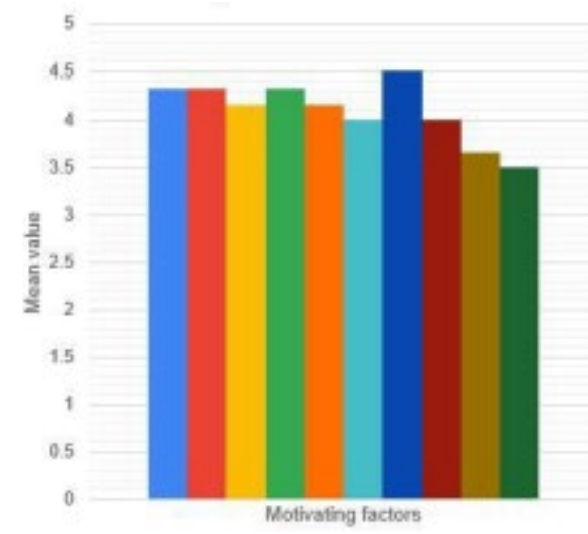

(a)Designer

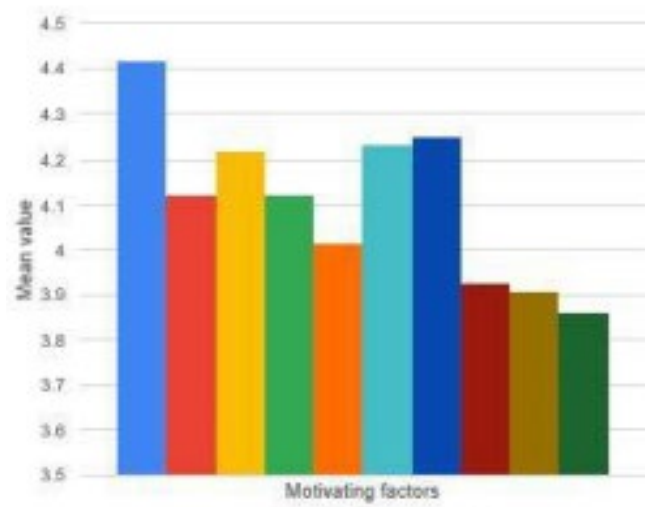

(c) Consultants

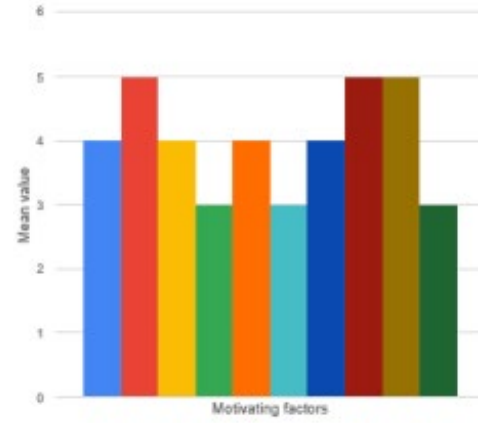

(e)Product manufacturers

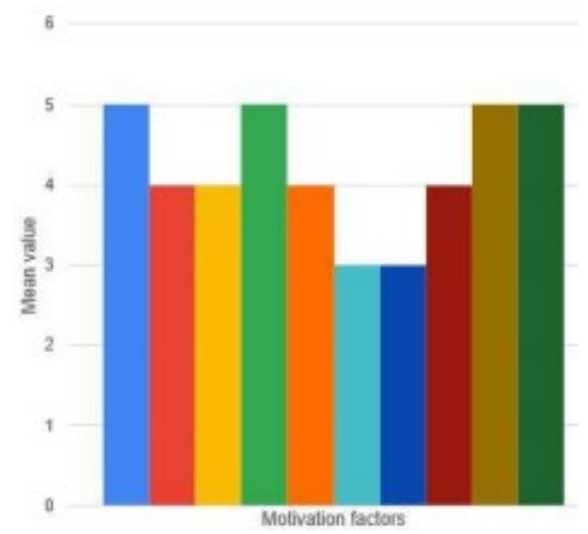

(b)Contractor

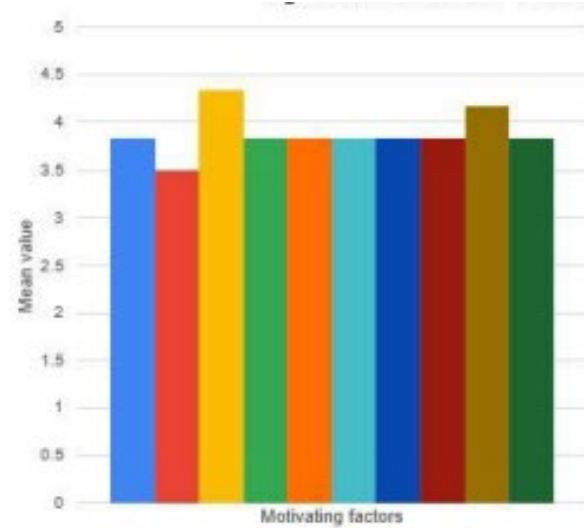

(d)Owner/client

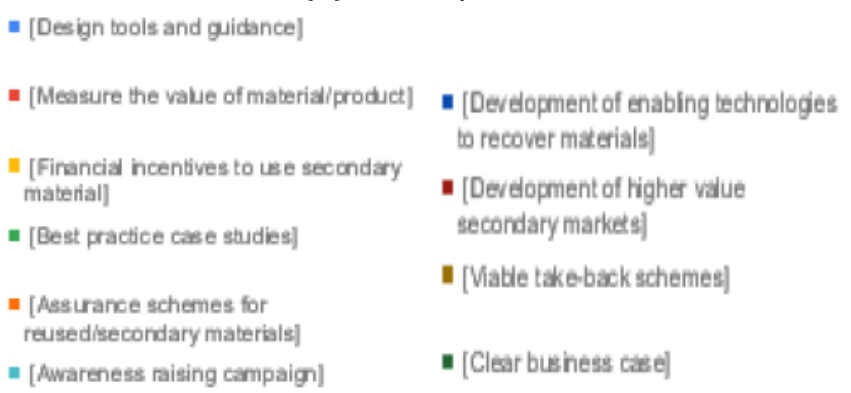

(f)Bar charts - Legends

Figure 8: Enablers mean value for different Indian stakeholders

Overall summary - More than 50 percent of people strongly agreed that proper design tools and guidance and provided incentives would motivate the most stakeholders in India. Whereas Agreed one is the material value measurement viability to increase its reusability. One

that is found neither agreed nor disagreed is the clear business case yet not much in number, but comparatively, it has a higher percentage of the vote. Some of the disagreed points are business plans, proper take-back schemes for material, and the creation of a secondary market. Most points are agreed/strongly agreed than they 
disagree/strongly disagree. Only one has a higher number vote for the strongly disagree that is secondary market value.

\section{Significant obstacles}

Overall summary - One of the most agreed ones is that the Lack of circular construction knowledge is the critical reason behind the non-adoption of circular construction. Building complexity, fragmented supply chain, and recovery market are some of the agreed points when

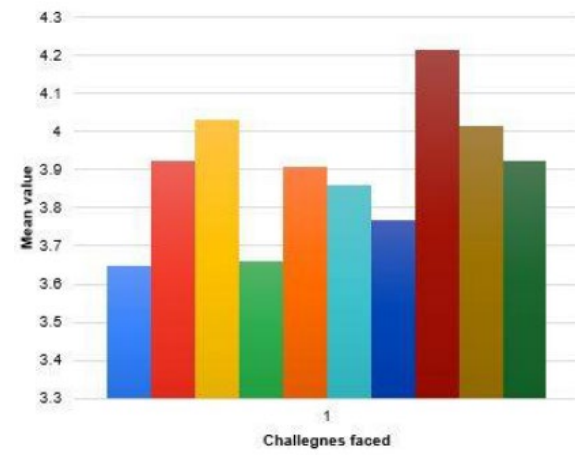

(a)Designer

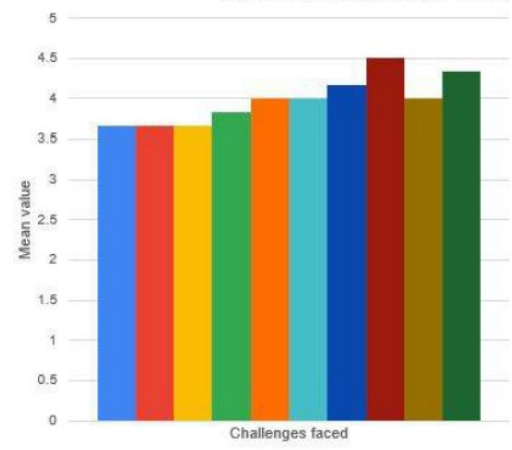

(c) Consultants

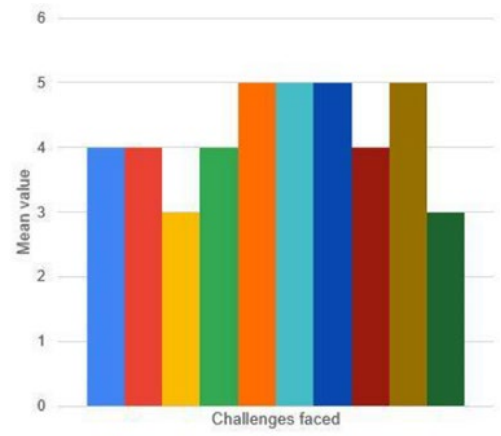

(e)Product manufacturers

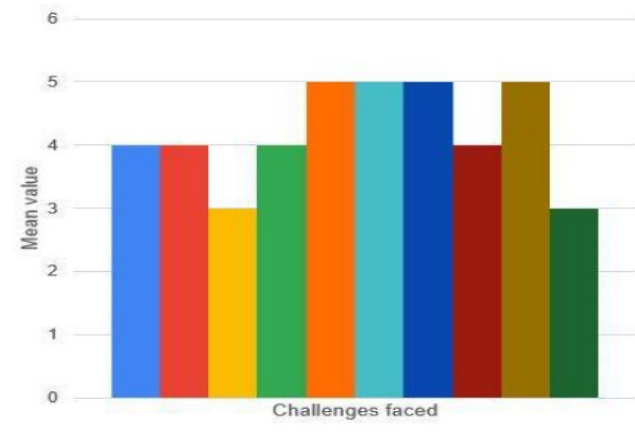

(b)Contractor

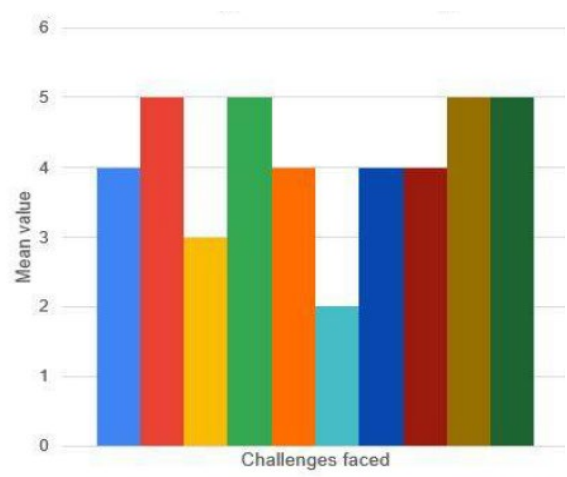

(d)Owner/client

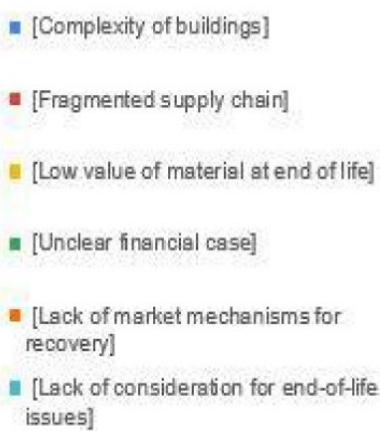

(f)Bar charts - Legends

Figure 9: Challenging factors among different stakeholder

discussing circular construction obstacles. Unclear financial case is considered as the intermediate one, which has been voted high in the significant obstacle in adopting the circular construction. Low market value and end life considerations are the disagreed ones in the significant obstacles. Strongly disagreed is the point which has obtained less vote and that has been made to interest lack. 
Impact of Circular Construction on Demolition Waste Management in The Indian Construction Industry

\subsection{DISCUSSION}

From the result, around 50 percent of stakeholders have some idea about what is circular construction. The data collected from the survey states that some important bottleneck points have to be addressed for implementing the circular construction in India. It was summed and classified broadly as Economic issues, Technology issues, Promotional and organizational issues. Moreover, to conclude the discussion, the required strategies has been listed for its adoption.

\subsubsection{ECONOMICAL ISSUE}

The circular construction buildings always possess materials of high value. However, some critical questions prevailing in the industry are the advancement of circular construction, which solves the built environment's fiscal issues. The products' value is highly uncertain once after the end of life, which is the major drawback in predicting the building's economic value. The predictability of construction products' value is highly uncertain, making it a highrisk factor for adoption. The construction product obtained at the end of life is always low value, making it uneconomical to reuse. Valuation of the buildings needs to be deeply understood for understanding the construction product's value at the end of life. Due to this adoption, even though the environmental harm is reduced, every developer's motivation is to adopt the profit model only. Like other sectors, circular construction needs alternative business models to get a viable economic case solution. The Development of an approach model for fetching maximum benefits in future use could increase the adoption among different stakeholders.

\subsubsection{TECHNOLOGY ISSUE}

Viable technology needs to be implemented to obtain the full benefits of circular construction. It is considered one of the significant factors that increase the product's value when reusing/recycling it in structure. The technology aspect becomes more challenging for the building, which has not been planned for circularity. This issue gets intensified when the building chosen for circularity is a unique building like an intelligent building where lots of small products are used to adopt the intelligence, which may not be reused or building that has been built in modern construction ways. For circularity adoption, durability, workability, and afterlife aspects during designing could improve the possibility. Knowledge shortness in design, components, and products used in construction affect the circularity. The material passports documents usage in the project could increase the adopting possibilities, but such documents are in the Indian construction industry's blooming stage.

\subsubsection{THE PROMOTIONAL AND ORGANIZATIONAL ISSUE}

One of the significant factors behind this organizational issue is the fragmented nature of the construction industry. The difficulty in the circularity is the circular material follows within the built environment. The profit obtained in adoption should be equally spread across the supply chain. Survey findings also strengthen that there is a lack of an incentive to design an afterlife. From the survey, the organizational issue faced in adopting the circular construction application is a Comprehensive approach, facility management, and afterlife approach activities.

Moreover, to increase resource usage efficiency and improve the supply chain, research has been undertaken. In-depth activity clarity is required for increasing the circularity in construction. BIM has been considered one of the best solutions for breaking this fragmentation in the construction industry. A collaboration that is considered one main facto can be improved and increase the circular construction adaptability using this BIM. It has more smooth data sharing capabilities without any lag in transfer instantly. The promotions among the different stakeholders could increase the adoption. There is a need for improvement in India as it is found lacking by around $80 \%$ of people. It can be improved through ongoing study or meeting among professionals; attractive incentives feature to increase its reachability, publishing about environment wealth current status will let every individual understand the seriousness in its adoption. 


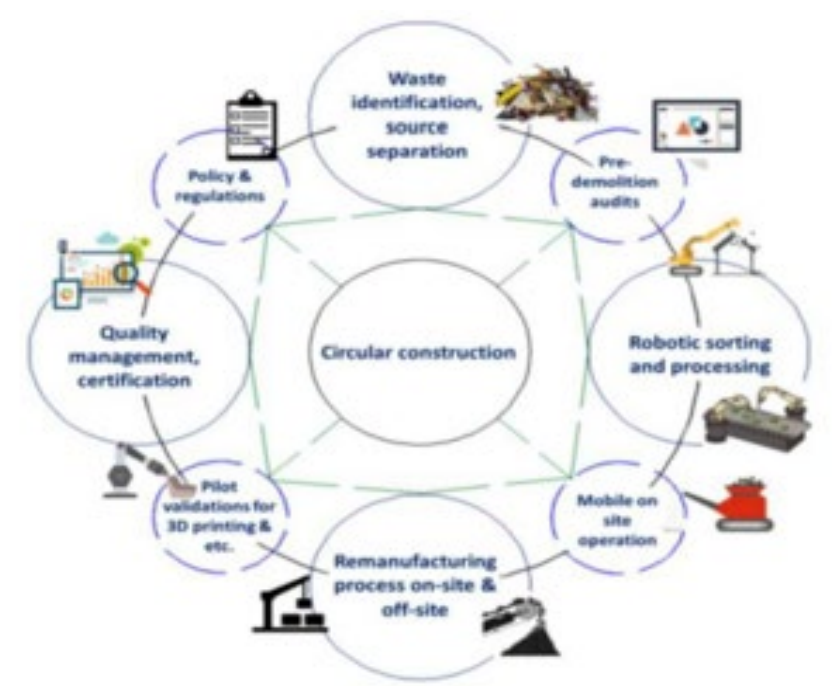

Figure 10: Strategies for circular construction adoption

Following are some of the strategies that are required for increasing the circularity in India

- Law enforcement \& Flexible regulation

- Increase competitiveness through creative designs

- Targets and achievement awards

- Innovative ideas required and possibilities in the current world

\section{CONCLUSION \& RECOMMENDATIONS}

A significant amount of research has been done on circular construction applications in the Indian context. These days, the circular construction idea gathers traction as an alleged innovative road to sustainable growth.[14] The Indian construction industry has especially endorsed the definition. Despite the increased publicity and support received so far, the Circular construction has seen minimal implementation. Even a few practicing stakeholders also complain about its implementation process due to many barriers in its usage. At present, no many good initiatives have been taken practically. The measurement of awareness among the practicing stakeholders; the issues faced in adopting is also not experimented with within India. The writer has found some significant enablers and obstacles (i.e., help in analyzing the circular construction adoption) faced by different Indian construction industry stakeholders for adopting circular construction. There is also a need for government measures concerning identified enablers and obstacles, such as reducing the subsidies for linear goods, while at the same time increasing the circularity through such as a reduced value-added tax (VAT), which provide the CE with a much-needed drive. Some of the findings in the research are

- Fewer initiatives from the government side

- The possibilities of economic and social dimensions of circular construction are significantly less explored in the Indian context.

- Exploration in material value measurement dimensions, and criteria in circular constructions, performance check, is not made in India. Circular construction needs to be explored in terms of an entire building rather than the material level.

- There are no specific targets that have been made by the government to stakeholders in circular construction.

Designer innovation increases the value of material during reusing or recycling. The principle of circularity becomes more problematic when it needs to be adopted in the demolition stage. The Government of India needs to take more initiatives by collaborating with budding researchers and practitioners to develop India's circular construction. The waste management department needs to be separate from the CDW management separately; 
Impact of Circular Construction on Demolition Waste Management in The Indian Construction Industry

currently, it is acting as a whole waste management unit in India-compelling the stakeholders through the appropriate tools and protocol help in imposing the circular construction in India. Artificial Intelligence shortly may assist in reducing waste. Techniques like smart or selective demolition need to be implemented through a law that enhances building components' reusability. The research can be taken further for framing the circular construction model framework that solves all the three issues mentioned in the discussion, which is more applicable in India. Moreover, that is easily understandable to all the stakeholders so that there is no hindrance in its adoption.

\section{SOURCES OF FUNDING}

This research received no specific grant from any funding agency in the public, commercial, or not-for-profit sectors.

\section{CONFLICT OF INTEREST}

The author have declared that no competing interests exist.

\section{ACKNOWLEDGMENT}

None.

\section{REFERENCES}

[1] M. H. Z. Faruqi and F. Z. Siddiqui, "A mini-review of construction and demolition waste management in India," Waste Manag. Res., vol. 38, no. 7, pp. 708-716, 2020, DOI: 10.1177/0734242X20916828.

[2] S. H. Ghaffar, M. Burman, and N. Braimah, "Pathways to circular construction: An integrated management of construction and demolition waste for resource recovery," J. Clean. Prod., vol. 244, p. 118710, 2020, DOI: 10.1016/j.jclepro.2019.118710.

[3] K. G. S. B. Vidyasekar, "Implementation of 3R Principle in Construction and Demolition Waste Management," Int. J. Innov. Technol. Explor. Eng., vol. 8, no. 12, pp. 977-980, 2019, DOI: 10.35940/ijitee.

[4] Building Materials and Technology Promotion Council, Utilisation of Recycled Produce of Construction \& Demolition Waste A Ready Reckoner. 2018.

[5] A. L. Narayanan and D. Srinivas, "GUIDELINES FOR THE FORMULATION OF INDIAN CODE OF PRACTICE FOR CONSTRUCTION AND DEMOLITION WASTES,” vol. 4, no. 1, pp. 5-10, 2016.

[6] K. T. Adams, "Circular economy in construction: current awareness, challenges, and enablers," vol. 170, pp. 15-24, 2017.

[7] P. Kamrath, Demolition techniques and production of construction and demolition waste (CDW) for recycling. Woodhead Publishing Limited, 2013.

[8] C. P. Ginga, J. M. C. Ongpeng, and M. K. M. Daly, "Circular economy on construction and demolition waste: A literature review on material recovery and production," Materials (Basel)., vol. 13, no. 13, pp. 1-18, 2020, DOI: $10.3390 / \mathrm{ma} 13132970$.

[9] J. Thomas and P. M. Wilson, "Open Access Construction waste management in India American Journal of Engineering Research (AJER)," pp. 9-12, 2013.

[10] "Circular Economy in Construction - Experiences from Finland," 2019.

[11] Central Pollution Control Board, "Guidelines on Environmental Management of Construction \& Demolition (C \& D) Wastes, Ministry of Environment, Forests \& Climate Change, Government of India.," vol. 1, no. March 2017.

[12] I. Standard, “Demolition of Buildings - Codeofsafety," Marg, no. December 1991, 1996.

[13] S. H. (Centra. P. H. and E. E. O. (CPHEEO)) Schneider, "Municipal solid waste management manual," Energy Conversion, Second Ed., pp. 73-79, 2017, DOI: 10.1201/9781315374192.

[14] J. Kirchherr et al., "Barriers to the Circular Economy: Evidence from the European Union (EU)," Ecol. Econ., vol. 150, no. December 2017, pp. 264-272, 2018, DOI: 10.1016/j.ecolecon.2018.04.028. 